\title{
The art of legislative drafting
}

by Geoffrey Bowman ${ }^{1}$

This is a slightly revised version of the Sir William Dale Memorial Lecture for 2005. It was given in the Senate House of London University on 7 November 2005 by Sir Geoffrey Bowman KCB, the First Parliamentary Counsel and a Bencher of Lincoln's Inn.

\section{INTRODUCTION}

I was honoured to be invited to give this lecture. Perhaps I was rash when I asked what I should talk about. I was invited to discuss the maxim that drafting is more an art than a science. In doing so I was asked to explain why the Parliamentary Counsel Office does not have a drafting manual, and to say something about the way legislative drafting will develop. This is quite a tall order. But (even worse) I was asked to begin with something about the philosophy of drafting.

\section{PHILOSOPHY OF DRAFTING}

I can dispose of the philosophy quickly. I decided to consult the works of someone who was both a lawyer and a philosopher, and I chose Francis Bacon. He gives a good reason why philosophers do not make good legislators. In The Advancement of Learning he says this -

"As for the philosophers, they make imaginary laws for imaginary commonwealths; and their discourses are as the stars, which give little light, because they are so high."

I think that the philosophy of drafting can be summed up in two rules (not coined by me) -

$$
\begin{aligned}
& \text { "One - decide what you want to say. } \\
& \text { Two - say it." }
\end{aligned}
$$

To expand on that a little, the basic idea is to find out what the client wants, analyse it to ensure that it stands up, and express what is needed in language that is as precise and clear as possible.

I would not want that simple summary to disguise the real effort that the job entails. An appropriate thought is one expressed by Bishop Stubbs. The first volume of his great Constitutional History was published in 1874. The preface opens with these rather forbidding words -

"The History of Institutions cannot be mastered - can scarcely be approached - without an effort."

Similarly, Acts and the study of Acts can be approached only with an effort. And this arises from the very nature of legislation.

\section{THE ART OF DRAFTING}

With all this in mind, let us turn to the theme that legislative drafting is more an art than a precise science. In the ninth century Agobert of Lyons, commenting on the different laws prevailing in much of Europe, said that five men meeting together might be subject to five different personal laws. This has a particular resonance with me because I often say that, if five drafters were set on the same Bill, each might emerge with a different product. It is true that there would normally be little of substance that differed between the drafts. And we would rarely feel that a colleague's efforts were plain wrong. But we might well say, "I would not have done it that way". Now, if five different drafters would produce five different Bills, it suggests that legislative drafting is an art rather than a precise science.

In essence I want to show that the composition of legislation has little of the mechanical about it. I also hope to give some idea of what it is really like to be a drafter. As Lord Rodger of Earlsferry once said to me, there is scope for letting more light shine in without spoiling the magic of the Parliamentary Counsel Office.

\section{ALL BILLS DIFFER - ANALYSIS}

One reason why drafting is an art is that all Bills are different. Private legal instruments (such as contracts or leases) are often based on precedents. The legislative drafter can very rarely draw on a precedent. Each Bill needs to be approached as a unique exercise. This is evident in the early stages of a Bill, when the drafter carries out his function of discovering the department's intention and analysing the proposed policy to see whether it works. In fact, this is one of his main tasks.

Let us take a simple example of this function. In the 1990s I drafted the legislation establishing landfill tax. One problem was to define a disposal by way of landfill. I was asked to follow some regulations which defined waste disposal operations. When I looked at the items I saw that one of them was (in effect) "tipping (for example landfill)". I said that we could not use this as part of a definition of

'The article "The art of legislative drafting" was written by Sir Geoffrey Bowman of the Parliamentary Counsel Office. It is published with the permission of the Controller of HMSO and The Queen's Printer for Scotland. 
landfill, because it referred to the very thing we were trying to define. To define landfill to include "tipping (for example landfill)" was rather like saying "an elephant is an animal (for example, an elephant)". Unless you know what an elephant is to start with, it gets you nowhere.

This is a simple illustration of the point that the drafter does not just do as he is bidden. If he believes that the suggested approach is wrong, he says so. Let me take a more homely example of the sort of questioning the drafter has to exercise. In Thomas Love Peacock's novel Headlong Hall the landscaping of grounds is discussed. $\mathrm{Mr}$ Gall refers to the characteristic of unexpectedness in a landscape. Mr Milestone asks how unexpectedness is apparent when a person walks round the grounds for the second time.

But drafters are not unique. Like other people, they are of course fallible. I drafted the poll tax legislation. At a fairly late stage somebody (not myself but a member of the instructing department) realised that we had imposed the tax on everybody, including people like monks who had made a vow of poverty and had nothing with which to pay. We came up with an exemption. I punished myself for not spotting the need for this. And I sometimes wonder how many issues like this slip through the net altogether.

Anyhow, my point is that part of the drafter's job is to carry out a ruthless analysis. All Bills are different, and each set of instructions requires its own individual analysis.

\section{CREATIVE FUNCTION}

My next point is that the drafter has a creative function. If the department's suggested approach does not work the drafter does not simply reject it. If possible, he offers something else - something that does work. In the case of landfill tax, after discussion with the department's officials I attempted a definition of landfill. It was direct, and it built on the simple basic idea of a deposit of material on or under land. I am glad to say that it worked.

But the drafter has to be careful, because it is not for him to make up the policy. I once drafted some provisions to deal with the misbehaviour of football fans. I suggested that a neat solution to football hooliganism would be to ban the game altogether. I suggested this very much tongue in cheek. But I think it illustrates the proposition that it is not the drafter's job to make up the policy, and that it should not be his job. At the same time, it is part of his job to offer workable solutions when possible.

The line between offering workable solutions (on the one hand) and making up the policy (on the other hand) is often a fine one. And a great deal of experience is needed to judge where it lies in a given case. Some drafters are prepared to go further than others in offering solutions. The same drafter may be bolder on some Bills than on others. Two different drafters may offer two different solutions. You cannot predict in the case of any given Bill where it is all going to lead.

Incidentally, if my ideas about policy on football were unacceptable I wonder how Dr Johnson would have fared as a policy maker. He once said this about marriage -

"I believe marriages would in general be as happy, and often more so, if they were all made by the Lord Chancellor, upon a due consideration of characters and circumstances, without the parties having any choice in the matter."

\section{ITERATION}

The process of analysis and coming up with a workable policy is sometimes called an iterative one. It involves throwing ideas back and forth between the drafter and the instructing department, whose administrators and lawyers will contribute ideas of their own. This iterative process is not simply an intellectual game. The whole object is to arrive at something that withstands examination in Parliament and in the courts. It is better that the ideas are tested and refined at the drafting stage than that they are torn apart later. Francis Bacon puts it well in his essay "Of Counsell". He is referring to "counsel" in the sense of advice. But he could equally be referring to Parliamentary Counsel. He says this -
"Salomon hath pronounced, that In Counsell is Stability.
Things will have their first, or second Agitation; If they be not tossed upon the Arguments of Counsell, they will be tossed upon the Waves of Fortune; And be full of Inconstancy, doing, and undoing, like the Reeling of a drunken man."

There is of course a certain pleasure in this iterative process. In discussing tavern discourse Dr Johnson puts it like this -

\section{"I dogmatise and am contradicted, and in this conflict of opinions and sentiments I find delight."}

So far, then, we have the points that all Bills are different; that the drafter has to analyse everything to ensure that it works; and that his role involves suggesting workable solutions but not straying too far into the process of making up the policy. The course which this iterative process takes is different for each Bill, and it cannot be predicted. I think these points help to illustrate the proposition that drafting is an art rather than a precise science.

\section{COMPOSITION - PRELIMINARY}

Having arrived at ideas that will stand up to analysis, the drafter has to express them. I think it is generally accepted that legal concepts and legal documents are often difficult to understand. In the case of legislative drafting the position is complicated by other factors. I want to mention two factors. One relates to the legislative audience. The other relates to the nature of legislation. 


\section{AUDIENCE}

First, then, there is the audience. In fact the drafter has several audiences. There will be administrative and legal civil servants, ministers, members of both Houses of Parliament, practising barristers and solicitors, and judges. There will also be the people the legislation affects. They may range over a wide area, and a lot depends on the nature of the Bill. At one extreme there may be specialists (such as tax accountants or pension experts or scientists). At the other extreme there may be laymen (perhaps lay members of a board established to promote the arts).

The result of all this is that, in the case of any given Bill, there will be an element of compromise and balance. For instance, in drafting a provision to block a sophisticated tax avoidance scheme the drafter's main concern will be to achieve certainty. That may involve sacrificing a degree of ready intelligibility so far as (say) members of Parliament are concerned. Striking the right balance in a given case involves a good deal of judgment. And this is another reason why drafting is an art rather than a precise science.

\section{NATURE OF LEGISLATION}

And then there is the peculiar nature of legislation. The drafter works in a stark literary environment, and he is denied some of the techniques allowed to other writers.

The nature of legislation was discussed by Sir Christopher Jenkins (then the First Parliamentary Counsel) in 1997 in a memorandum to the select committee on the modernisation of the House of Commons. I am drawing (gratefully) on what he said.

An Act has a precise and narrow object, which is to change the law - no more and no less. It is not designed to offer the things that other forms of writing offer (such as entertainment, information, explanation, argument or stimulation).

So an Act cannot employ all the usual techniques of composition. For instance, it cannot say the same thing twice merely to emphasise it. If it did, the reader would wonder whether something stated only once was to have equal effect. Nor can an Act say something twice but in different words. If it did, the reader would wonder whether it was trying to get across one message or two different ones.

The consequence of all this is that the language of Acts is tight and spare, and every word will be assumed to have a purpose. So Acts can be approached only with an effort.

The stark literary background which Sir Christopher describes brings to my mind a passage from Francis Bacon's essay “Of Studies”. He says this -

"Some Bookes are to be Tasted, Others to be Swallowed, and Some Few to be Chewed and Digested: That is, some Books are to be read onely in Parts; Others to be read but not
Curiously; And some Few to be read wholly, and with Diligence and Attention."

I would put statutes in the third category - that is, of books that are to be chewed and digested, to be read wholly and with diligence and attention. This is a factor that arises largely from the very nature of legislation.

\section{EXPLANATORY MATERIAL ETC}

In recent years there has been a good deal of discussion concerning the nature of legislation. Much of the discussion has tended to concentrate on purpose provisions and explanatory material.

Purpose provisions occur where the drafter expresses the detailed rules and also states their purpose. For instance, a tax provision might state, "this section is enacted to prevent the avoidance of tax" and then proceed to set out the specific rules designed to achieve that purpose. The main danger is that the relationship between the two sorts of provision is not clear. A declaration that a section is enacted to prevent tax avoidance might lead some readers to construe the precise rules one way and other readers to construe them another way. Other readers might conclude that the declaration has no effect in law. The drafter should avoid this potential confusion. He can make his intention clear in the specific rules themselves and leave out the purpose provision.

Purpose provisions (if included in the legislative text at all) are designed to be part of the operative legislative material. Explanatory provisions are (as I understand it) not meant to be part of the operative provisions. One danger of explanation is that it might be couched in such general terms as to be incomplete and therefore misleading. Suppose an explanatory overview states that a transferee becomes subject to tax if he becomes nonresident. But suppose that when you get to the operative provisions you find that the tax charge arises only in certain cases of non-residence. If the explanatory overview causes the reader to adopt the wrong assumption, it can cause him trouble rather than help him. Another danger is that, if the operative provisions are amended as the Bill goes through Parliament or after enactment, the explanatory material will be out of step unless that is amended too. The need for that can be overlooked, especially if amendments are made in a hurry (as they sometimes are).

The general view in the United Kingdom is that the best place for explanatory material is in the explanatory notes that now accompany Bills and Acts. As for purpose provisions, I do not think there is a general acceptance of their utility. And in 2004 the House of Lords select committee on the constitution recommended that they should not be included in Bills but that the explanatory notes should state the purpose.

My own view is that the legislative text should be confined to doing so much as is needed to change the law. Then the 
reader knows that all the words count and are of equal weight. Purpose provisions and explanations are too unruly to include in the text of the Bill. The risk is that they create obscurity. This view is not new. For instance, in the sixteenth century Lucas de Penna deplored empty phrases in laws, because they can obscure the object. I think we can take "empty phrases" to include material not designed to meet the precise object of changing the law (such as purpose provisions) and material not intended to have legislative effect at all (such as explanatory provisions).

I often envy writers to whom a wide variety of techniques is available. For instance, a textbook might help the reader by giving a summary of difficult technical passages. That technique would not be available to the legislative drafter, who operates in an environment where all the words count and have equal weight. Nor would a modern drafter adopt the exuberant repetition and emphasis evident in this provision of an Act of Richard III -

"It is ordered that the statute be annulled and utterly destroyed, taken out of the Roll of Parliament, and be cancelled and burnt, and be put in perpetual oblivion."

So the drafter's literary environment is a stark one. Statutory language is by its nature compressed and spare. The drafter is generally denied some of the techniques available to other writers - such as repetition, explanation and emphasis. One result is that the drafter relies heavily on the techniques that are available to him. I now turn to discuss some of the techniques employed by the legislative drafter.

\section{STRUCTURE}

Before I get to the wording I want to say something about the structure of a Bill. In the case of many Bills there is no "right" structure. There are often several possible ones, and the choice is up to the drafter. He will take pains to present the material in a way that is logical and that puts the reader to as little trouble as possible. In the case of some legislation, complex provisions are inevitable. But the drafter can help the reader if the initial provisions are easy and he is led gently to the inevitable complexity.

Let us take landfill tax as an instance. A tax has three essentials. They are the charge (that is, the situation in which something is subjected to tax), the person who must pay, and the amount charged. In the case of landfill tax, the first four sections deal briefly with these three elements. They secure that tax is charged on a taxable disposal, defined as a disposal of waste by way of landfill at a landfill site. They also secure that the landfill site operator must pay. And they secure that the amount charged is so much per tonne disposed of.

After reading these four relatively easy sections, the reader will have a good idea of the basic structure of the tax. Some concepts need elaboration, but this comes later.
For instance, there are definitions of a disposal as waste, a disposal by way of landfill, a landfill site, and an operator of a landfill site.

The reader is given the basic information in easy stages at the outset. He is not bombarded with detail at the beginning. Life is made easy for a reader coming to the provisions for the first time. It would have been possible to elaborate on each element as it cropped up. But then the reader would not have found it as easy to get an immediate bird's eye view. And I felt that such a view was important, especially for a new tax. The important point is that the choice of how to structure the draft is generally for the drafter. It involves judgment, and there are no hard and fast rules.

And, of course, the drafter's ideas are by no means always acceptable. When I was drafting another new tax it seemed to me that we could devise a better, simpler structure than the one the department suggested. But I was told that we had to adopt the department's structure, which sprang from a policy requirement for the tax to follow accountancy practice.

So the drafter is sometimes denied the freedom to practise his art. But where he is allowed freedom he will take great pains over structure. And sometimes he will have the nagging feeling that he should have taken a different course. My suspicion is that readers of legislation are often unaware of the amount of trouble that the drafter takes over structure.

\section{WORDING}

I come now to the language used by the drafter. Here it is possible to make various suggestions. But there are very few hard and fast rules.

There has been much discussion in recent years concerning plain language. I take this to mean language that is as precise, clear and simple as the subject matter will allow. A student wrote to me recently, asking whether there is a move towards plain English in the legal profession and how long it will take to change over completely to it. I replied that a lot depends on what is meant by plain English, and that developments in language never cease. I continued, "So perfection is both incapable of definition and unattainable. You just have to do your best in the particular circumstances facing you, and each Bill requires different techniques."

Anyway, it is pleasing that the efforts of the Parliamentary Counsel Office are recognised. In 2004 the House of Lords select committee on the constitution commended "the efforts of parliamentary counsel in rendering bills in more accessible language".

So the general idea is to express thoughts in language that is as precise, clear and simple as the circumstances allow. Let me now discuss just a few of the helpful drafting techniques that are familiar to drafters. In this way I hope 
to illustrate the general point that there are very few hard and fast rules. Everything depends on the particular circumstances facing the drafter, who has to exercise judgment.

\section{LENGTH OF SENTENCES}

The first technique relates to the length of sentences. To understand a long sentence the reader may need to re-read it several times and mentally divide it into digestible smaller sentences. The drafter should generally save the reader the trouble by dividing it up for him. Some people suggest that a sentence should not exceed a given number of words. Opinions vary on the number. It might perhaps be 20 or 25 or 30 . But, whatever it is, any suggestion can be no more than a guide. In any event, generally speaking Bills are now drafted in short sentences.

However, it is not always desirable to draft in short sentences. For instance, a long sentence may be desirable to avoid tedious repetition. This might occur where there is a list of prohibited activities, and it may be absurd to repeat the prohibition for each separate activity. Section 11(1) of the Chemical Weapons Act 1996 reads -

"No person shall -

(a) construct premises he intends to be used to produce chemical weapons;

(b) alter premises in circumstance where he intends that they will be used to produce chemical weapons;

(c)

The subsection then proceeds for eight paragraphs in all, listing different prohibited activities. It would be absurd to have eight separate subsections, each beginning with "No person shall”.

However, there is a qualification. This is that, if you do use a long sentence, you need to take care. For instance, it is best not to let a subject and its verb become separated by a lengthy phrase. If it is, the reader may lose the connection between them. So a structure like this should be avoided -

"A person who-

(a) conceals criminal property,

(b) disguises criminal property,

(c) converts criminal property,

(d) transfers criminal property, or

(e) removes criminal property from England and Wales or from Northern Ireland,

commits an offence."

The construction adopted in section 327(1) of the Proceeds of Crime Act 2002 is better -

"A person commits an offence if he -

(a) conceals criminal property,

(b) [and so on]".
In that case the reader is told the point straight away (that an offence is committed). He does not have to wait until the end of a long proposition in order to find out.

So, the proposition that sentences should be short needs qualification - for instance, where a series of short sentences would produce absurdity and a long sentence would avoid absurdity. But the qualification itself needs qualifying, in that if you do use a long sentence you should take care - for instance, not to separate a subject from its verb.

But the real point is that these are just a few thoughts. I doubt whether anyone would be able to come up with a set of rules that applied to every conceivable case facing the drafter. In the end he will have to take each case as it comes and exercise his judgment.

\section{POSITIVE OR NEGATIVE}

The second technique is to prefer positive statements to negative ones. They are usually easier to understand. They are likely to be more direct and straightforward. For instance, the second of these phrases is easier to follow than the first -

"A tenant, other than one who does not have a lease for more than three years, must register his rights."

"A tenant who has a lease for more than three years must register his rights."

But it would be wrong to try to express everything as positive statements. In particular, a double negative does not always equate to a positive. For instance, these two sentences do not have the same meanings -

"The appeal may proceed only if the tribunal has not certified that the appeal is not validly made."

"The appeal may proceed only if the tribunal has certified that the appeal is validly made."

Nor can a negative always be simply converted into a positive that corresponds to it (or apparently corresponds to it). That can easily change the meaning. A colleague once drafted a Bill about shipping. It contained a reference to a ship that was not a British registered ship. A reader felt that this was inelegant, and that the reference should be to a foreign registered ship. But he had overlooked the fact that many ships are not registered at all. The drafter's Bill caught these, but the reader's version would not. The reader's version was simpler, but it produced the wrong result.

So the drafter needs to take great care. Each case depends on its own circumstances. You cannot lay down rules applicable to all cases.

\section{ACTIVE OR PASSIVE}

The third technique I want to mention is to prefer the active voice to the passive. Readers generally find it easier 
to understand. For instance, the second of these is easier than the first -

"If a notice which satisfies the prescribed conditions is served by the Secretary of State....."

"If the Secretary of State serves a notice which satisfies the prescribed conditions....."

Another factor is that the passive tends to conceal. For instance, if you say "notice must be given" before a particular date, it is not clear who must give the notice. If the active voice is used ("x must give notice") the drafter and those instructing him at least have to think who " $\mathrm{x}$ " is supposed to be.

But it would be wrong to assert that the drafter must always use the active. Sometimes he uses the passive deliberately. For example, a provision might say that "if the council serves a notice, and a counter-notice is served on it, the council may not proceed". Here the passive may be deliberate because it does not matter who serves the counter-notice.

So there is no automatic rule that everything should be expressed in the active rather than the passive. The golden rule is that you need to think about each case on its merits.

\section{DRAFTER'S FALLIBILITY}

In choosing the wording, as in other matters, drafters are of course fallible. I drafted the Sale of Goods Act 1979, which consolidates the previous law. The Act applies to all contracts made on or after 1 January 1894 (when the 1893 Act came into operation). So section 1(1) of the 1979 Act reads -

"This Act applies to contracts of sale of goods made on or after (but not to those made before) 1 January 1894."

After the Act was passed someone pointed out a glaring ambiguity. Was it the contract or the goods that had to be made on or after 1 January 1894? Internal evidence within the Act shows that the provision means (as intended) the contract. But I could have avoided the ambiguity.

\section{CHANGING LANGUAGE}

I have now illustrated some of the techniques available to the drafter. And I hope I have illustrated the proposition that he has to exercise a good deal of judgment. You cannot lay down rules capable of applying in every conceivable instance. Another factor is that language is always changing, and statutory language is no exception. In this way improvements are made. It would be wrong to hinder progress by seeking to lay down rules.

For instance, the traditional style of drafting tended to bind propositions by references back to other ones. This is often unnecessary, because successive propositions are naturally read together anyway. For instance, subsection (1) of section 3 of the Transport Act 2000 provides that -
"A person commits an offence if he provides air traffic services in respect of a managed area."

Subsection (3) then provides for an exception if "the person is authorised by an exemption to provide the services". At one time the exception might have been expressed in terms of "the person referred to in subsection (1) above" and "the services referred to in subsection (1) above". Or it might have been expressed in terms of "the person concerned" or "the services concerned". As it is, the references are simply to "the person" and "the services". There is no need for more where the context makes it clear who or what is being referred to. I do not know when drafters started to omit the unnecessary clutter. But I am glad that they felt able to do so. It would have been unhelpful to have a rule that cross-references are always necessary or desirable. The absence of such a rule left drafters free to experiment with new techniques - or, to put it another way, to practise their art.

Taking another example of change, many provisions used to start with expressions like "Subject to subsection (2) below". This will distract the reader from the main proposition. It is often best to state the main proposition first and then to state the exception. And in appropriate cases the exception can be preceded by a word such as "But". For instance, section 10 of the Transport Act 2000 reads -

"(1) No action is to lie in respect of a failure by a licence holder to perform -

(a) a duty imposed by section 8;

(b) a condition of a licence.

(2) But subsection (1) does not affect -

(a) a right of action in respect of an act or omission which takes place in the course of the provision of air traffic services;

(b) $\ldots \ldots \ldots$,

I do not know when drafters first adopted this more direct approach. But I am glad that they felt able to try out new ideas. In fact I believe that in many cases there is no need even for a word like "but". In the example I have just given the "but" could easily be dropped, because the words "subsection (1) does not affect...." do all that is needed.

We have to accept that some experiments might not find favour. Let us consider an experiment. In private documents we sometimes find the reader addressed as "you". For instance, some insurance contracts address the insured person as "you". This device is used little in statutes. But there is at least one instance in a recent draft Bill. Provisions which set out the general duties owed by a director of a company to the company use the second person ("you"). For instance -

"As a director of a company you must exercise reasonable care, skill and diligence."

At first this seems to be a reasonable use of the second person. The provisions are addressed to the director 
because he is the person who must fulfil the duties. And there is a directness about the style that appeals.

On the other hand, most statutes are directed at more than one person. Even the provisions about directors' duties are meant for consumption by people in addition to the director. For instance, there are lawyers and accountants who advise the company and those who advise the director, and there are the courts. These people have to make a mental adjustment when reading the legislation if it is addressed to "you". There is also the point that "you" is not apt if the director is itself a company (which is possible). The result is that the experiment found little favour. And the device was dropped from the Bill.

The important point is that changes in drafting come about because drafters do not slavishly follow pre-ordained techniques. They feel able to practise their art in the way they see fit. They feel free to experiment. And they feel free not to proceed with an experiment.

\section{DRAFTING MANUAL}

Let me try to summarise. All Bills are different. All ideas for legislation need analysis and creative ideas from the drafter, and you cannot predict where the iterative process will lead you. The nature of legislation is unusual because its object is limited. This means that the drafter operates in a stark and precise literary environment, where he is denied some of the techniques available to other authors. In using the techniques that are available to him, there is no automatic solution and everything requires judgment. Language and techniques change all the time, and I hope they always will. In short, legislative drafting is more an art than a precise science.

The Parliamentary Counsel Office does not have a manual seeking to tell drafters how to do the job. We do have Office manuals on a number of topics, such as various aspects of Parliamentary procedure. But there is not much Office know-how on drafting itself. Maybe this is partly attributable to the British dislike of writing rules down. But I think there is more to it than that. There are good reasons for not writing rules down, or at least for not having a rigid manual. One is that the very nature of the job means that there is limited scope for learning things from books or manuals. You cannot lay down rules for every conceivable situation. Another reason is that techniques, language and general approach change and must be allowed freedom to do so.

On the other hand, it is possible to offer some guidance on drafting. And various developments are taking place in the Parliamentary Counsel Office. First, we have for some time offered seminars to trainees to supplement our system of training on the job. And we are beginning to incorporate guidance on modern drafting techniques. But this amounts only to suggestions, and nothing is prescribed.
Secondly, we have been wondering whether there are matters on which drafters could (or should) achieve greater consistency. Do our readers wonder why different drafters adopt different approaches even on relatively minor things? Take an apparently simple example. Suppose you use a section to insert a paragraph into a Schedule in another Act. You will end the inserted paragraph with a full-stop and closed quotation marks. Do you add another full-stop after the closed quotation marks, to end the section itself? Some people feel strongly that you should, because the rules of punctuation strictly require it. Others (such as myself) think you should omit the second full-stop, because it looks ugly and because there is no doubt that the thought has come to an end.

The passions raised by this issue remind me of the passage in Gulliver's Travels where Swift discusses the "obstinate war" between the two great empires of Lilliput and Blefuscu brought about by a disagreement. Many people have died in the war, and Swift tells us that "many hundred large volumes have been published upon this controversy." And what was this disagreement? It was over whether eggs should be broken at the bigger end or the smaller end. Pope put the sentiment more succinctly in The Rape of the Lock when he said -

"What mighty contests rise from trivial things".

Taking a more complex example, there is the legislative "shall". Traditionally, Acts contained phrases like "It shall be the duty of the Secretary of State to keep the arts under review (or whatever)". But the word "shall" is not generally used (outside legal documents) in this sense. In common speech it is generally taken to imply a statement about the future rather than to impose an obligation. In my view it is often enough simply to say, "The Secretary of State must...." And a phrase like "This Act shall extend to England and Wales only" can be expressed as "This Act extends to England and Wales only". On the other hand it is difficult to replace the legislative "shall" in setting up a statutory body. For instance, section 1(1) of the Scotland Act 1998 provides that -

\section{"There shall be a Scottish Parliament."}

But I know that the legislative "shall" can arouse deep passions. Some drafters are sticking to it more than others. Perhaps I had better leave it at that.

The point is whether there is room for greater consistency within the Office on a range of fairly standard matters. We have now set up a drafting techniques group in the Office to consider this, and their work is well under way. They have produced valuable papers on a number of matters. Let me give two instances.

First, there is the question of extent. An Act is assumed to extend to all the United Kingdom unless it states otherwise. So why (for instance) do some Acts intended to extend to Northern Ireland expressly so provide, and why do some refrain from so providing? Is the difference in 
practices justified? Secondly, there are the words introducing Schedules. Why (for instance) do clauses that introduce amendment Schedules use different approaches? Some examples are -

"Schedule 4 (minor and consequential amendments) has effect."

"Schedule 3 contains minor and consequential amendments."

Should we be consistent in matters like this?

Incidentally, in one of the group's papers (on paragraphing) I find these wise words: "legislative drafting does not lend itself to hard and fast rules..... different solutions may work better in different contexts." And that brings me to a very important point. It is not intended that the work of the group will go beyond suggestions. There will be no seeking to impose rules on drafters. There are two reasons why you cannot (or at least should not) go further. One is that all Bills are different, with their own unique problems, and it is not possible to formulate rules covering all imaginable cases. The other is that you must leave room for techniques and approaches to develop and improve.

\section{THE FUTURE}

As for the future, nobody knows. But we can guess. I believe that training drafters on the job over several years will remain the backbone of our training system. There may be a call for more systematic teaching of modern drafting techniques. There may be room for greater consistency on some matters. Whatever emerges will be confined to suggestions. It will not be prescriptive. Drafters will continue to experiment and to make improvements. No doubt they will try things they later regret. But drafting will never become a mechanical task capable of conforming to set rules. And change will never stop. Drafting will always be an art.

\section{CLARITY OF THOUGHT AND ANALYSIS}

Above all, it will always be the clarity of thought and the depth of analysis that matter most. And you cannot become skilled in these by reading manuals. If the basic analysis or thinking is unsound, the draft will be unsound. As Doctor Johnson said -

"Most men think indistinctly, and therefore cannot speak with exactness.”

But if the analysis is sound, and the thinking is clear, clarity of expression will often follow. You can learn a certain amount from studying various techniques. But in the end you just have to do your best in the particular circumstances facing you, and each Bill requires different techniques (to quote myself when I advised the student asking about plain English).

\section{PHILOSOPHY}

We started with philosophy, and we shall end with it. The thought of philosophy tends to bring to my mind a passage in Boswell. A certain Edwards, who was at Pembroke College Oxford with Doctor Johnson, says -

"You are a philosopher, Dr Johnson. I have tried too in my time to be a philosopher; but I don't know how; cheerfulness was always breaking in."

The following observation of Doctor Johnson the philosopher seems particularly appropriate after I have talked for the best part of an hour -

"The utmost which we can reasonably hope or fear, is to fill a vacant hour with prattle, and be forgotten."

Sir Geoffrey Bowman KCB

First Parliamentary Counsel; Bencher, Lincoln’s Inn 